\title{
Predicting Key Factors Affecting Outpatient Satisfaction in Public Hospitals: Evidence from Erzurum, Turkey
}

\author{
Ömer Alkan ${ }^{1}$, Ali Kemal Çelik ${ }^{1} \&$ Erkan Oktay $^{1}$ \\ ${ }^{1}$ Department of Econometrics, Atatürk University, Erzurum, Turkey \\ Correspondence: Ömer Alkan, Faculty of Economics and Administrative Sciences, Department of Econometrics, \\ Atatürk University, Erzurum, 25240, Turkey. Tel: 90-442-231-2086. E-mail: oalkan@atauni.edu.tr
}

\author{
Received: October 13, 2014 Accepted: February 25, 2015 Online Published: May 16, 2015 \\ doi:10.5539/ass.v11n13p117 URL: http://dx.doi.org/10.5539/ass.v11n13p117
}

This paper is a revised and extended version of the conference paper presented at "9th International Statistics Day Symposium", on 10-14 May 2014, Side/Antalya, Turkey.

\begin{abstract}
The main purpose of this paper is to determine background demographic and socio-economic factors affecting outpatient satisfaction of public hospitals. The present study utilized data from a written-questionnaire administered to six hundred and one adult patients who had received outpatient care at various units of three Turkish pubic hospitals. The dependent variable used in predicting student satisfaction was satisfaction levels of the respondents. Due to the ordinal nature of the dependent variable, an ordered logit model was performed to examine demographic and socio-economic determinants of outpatient satisfaction in Erzurum, Turkey. Ordered logit estimation results revealed that type of hospital, marital status, age group, education level, occupation, residential place, monthly income, and information about private hospitals were statistically significant factors of outpatient satisfaction. This paper attempts to present factors affecting outpatient satisfaction in a municipality which was adopted as the leading health care service provider of its region where little work was done. Considering its geographical location, the results of this substantial region may be a valuable contribution for health care managers and policy makers.
\end{abstract}

Keywords: outpatient, satisfaction, public hospital, ordered logit model, Turkey

\section{Introduction}

Turkish health care system has experienced a substantial transformation since the declaration of Urgent Action Plan on 16 November 2002 with a motto of "Health for All". Following this action plan the Health Transformation Program was prepared and announced in the early 2003 confronting the socio-economic requirements of the country and aiming global improvements. As the evaluation process is one of the most crucial phases of the Health Transformation Program, citizen satisfaction is considered as one of the major objectives of this program. Therefore, health care providers and policy makers purpose to develop essential health care policies by paying attention on health takers' evaluation of the health systems. During these evaluations several key factors affecting patient satisfaction including the waiting time, the complexity of health care operations and procedures, time period allocated per patient, courtesy of health care staff, etc. as well as patients' demographic and socio-economic characteristics are examined (Turkish Ministry of Health, 2009).

Health care quality has an impact on patient satisfaction which also contributes to positive patient behaviors such like loyalty or revisit intention (Naidu, 2009). Several characteristics that may be associated with patient satisfaction including patient expectations, health status, personal, and health system characteristics explicitly demonstrate the complexity of patient satisfaction phenomenon (Hsieh \& Kagle, 1991). Patient satisfaction surveys are frequently used as an indicator of quality of health care, whilst their reliability and validity have been somewhat subject to debate by earlier research (Scott \& Smith, 1994; Williams, 1994; Avis et al., 1997; McKinley et al., 1997; Sitzia, 1999; Staniszewska \& Ahmad, 1999; Dufrene, 2000; Grogan et al., 2000; Sun et al., 2001; Levin, 2005; Gill \& White, 2009; Mpinga \& Chastonay, 2011). In general, some criticisms against patient satisfaction surveys may arise as they uncover widespread and general dissatisfaction and the responses may be ill-considered (Demir \& Celik, 2002; Fitzpatric, 1991). On the other hand, patient satisfaction surveys 
are considered to be a very effective management and marketing tool which may be widely used to listen the voice of the consumers and understand their views (Mohd \& Chakravarty, 2014).

The main objective of this paper is to explore potential key factors affecting patient satisfaction with a particular focus on outpatient satisfaction in public hospitals. The rest of the paper proceeds as the following. The next section reviews the existing literature concerning the patient satisfaction and its influencers. The detailed estimation method was examined in the methodology section. The corresponding section also gives information about the sample design and data collection. The following section introduces the analysis results involving descriptive statistics, estimation results, and model specification. The last section concludes with discussion of results regarding the existing literature, recommendation for further research and implementation for current and further policy making.

\section{Literature Review}

The association between patient satisfaction level and demographic and socio-economic factors has been extensively experienced in the existing literature. Many previous research (Cohen, 1996; Sun et al., 2000, 2001; Jackson et al., 2001; Johansson et al., 2002; Rahmqvist, 2001; Demir \& Celik, 2002; Nguyen Thi et al., 2002; Cheng et al., 2003; Scotti \& Stinerock, 2002; Bikker \& Thompson, 2006; Hekkert et al., 2009; Laal, 2013; Farley et al., 2014; Mercer et al., 2014) found that patients' age was a significant factor affecting overall patient satisfaction. Marital status (Demir \& Celik, 2002; Thi, 2002; Laal, 2013) was also found as a contributor of patient satisfaction by some other studies. Other earlier research (Taner \& Antony, 2006; Tateke et al., 2012) indicated that patients of private hospitals were more satisfied than public hospitals. Patients' education level was determined as an important contributor of patient satisfaction by earlier studies (Demir \& Celik, 2002; Johansson et al., 2002; Cheng et al., 2003; Bikker \& Thompson, 2006; Hekkert et al., 2009; Al-Borie \& Damanhouri, 2013; Laal, 2013; Farley et al., 2014; Çelik et al., 2014). Some prior work (Thi et al., 2002; Oluwadiya et al., 2010; Al-Borie \& Damanhouri, 2013; Chang \& Chang, 2013) found that men tended to be more satisfied than women, in contrast with other studies (Kaldenberg, 2001; Laal, 2013; Çelik et al., 2014). Occupation (Al-Borie \& Damanhouri, 2011; Laal, 2013; Mohd \& Chakravarty, 2014), current residence (Laal, 2013), and income level or social class (Cohen, 1996; Frank et al., 2009; Al-Borie \& Damanhouri, 2013) were also found as significant key demographic factors affecting patient satisfaction with health care services.

A most recent study (Chahal \& Mehta, 2013) describes patient satisfaction as a multi-dimensional structure involving physical maintenance, physician care, nursing care and internal facilities. In that context, along with patients' demographic characteristics, courtesy of physicians or nurses were highly cited by previous research. Physicians' or nursing care including the courtesy of health care staff and trust in a physician were extensively studied (Cohen, 1996; Boudreaux et al., 2000; Dufrene, 2000; Jenkinson et al., 2002; Scotti \& Stinerock, 2002; Brown et al., 2005; Taner \& Antony, 2006; Andaleeb et al., 2007; Baalbake et al., 2008; Kim et al., 2008; Miranda et al., 2010). Past studies (Boudreaux et al., 2000; Merkouris et al., 2004; Johannessen et al., 2011; Tateke et al., 2012) underlined those health care providers' experiences and technical skills had a significant impact on patient satisfaction. Meanwhile, waiting time for health care was significant in the literature (Boudreaux et al., 2000; Brown et al., 2005; French et al., 2014; Mercer et al., 2014). Some past studies (Demir \& Celik, 2002; Jenkinson et al., 2002; Scotti \& Stinerock, 2002; Merkouris et al., 2004; Baalbake et al., 2008; Kim et al., 2008; Miranda et al., 2010; Johannessen et al., 2011; Otani et al., 2012; Tateke et al., 2012; Chang \& Chang, 2013; Gok \& Sezen, 2013) found that hospital facilities were significant contributing factors.

\section{Method}

\subsection{Ordered Logit Model}

Qualitative response models are one of the most frequently used statistical models as they enable the researchers to describe the behavior of individuals through a well-established sample survey data. The main objective of the qualitative response models is to specify the probability distribution of one or more discrete dependent variables as a function of independent variables (Amemiya, 1994). Special multivariate analysis for ordinal data seem to be a useful alternative as it is obliged to control possible influencing factors is required. Possible response of quality of satisfaction questionnaires on a generally Likert-type scale in five or seven points corresponds to an ordinal dependent variable with a single dimension (Abreu et al., 2008). Since the outcomes are clearly ordered, the researcher should consider the fact that the dependent variable is both ordinal and discrete. When the dependent variable shows these two characteristics simultaneously, ordered logit and probit models are the most frequently used and convenient methods to estimate models with more than two outcomes (Borooah, 2002).

For constructed binary variables, the basic equation of the ordered model can be written by: 


$$
\begin{aligned}
& w_{i j}=1 \text { if } y_{i \leq j}, \text { Ootherwise }, j=1,2, \ldots, j-1 \\
& P R\left(w_{i j}=1 / x_{i j}\right)=F\left(x_{i}^{\prime} \beta-\mu_{j}\right)
\end{aligned}
$$

where $w_{i j}$ is endogenous in the model. Equation (1) defines a set of $J-1$ binary choice models with different constants but common slope vector $\beta$. This equality is called the parallel regression assumption. The Wald test statistic is one of the most useful tests of the parallel regression assumption in Equation (1). In principle, $J-1$ binary choice models can be separately fitted, while each of these models produce their own constant terms and the consistent estimators of the common $\beta$. Herein, Brant's Wald test will moderate to explore the linear restrictions $\beta_{1}=\beta_{2}=\ldots=\beta_{j-1}$, or $H_{0}: \beta_{a}-\beta_{1}=0$, for $q=1,2, \ldots j-1$. As a result the Wald statistic is given by:

$$
\chi^{2}[(J-2) K]=\left(R \widehat{\beta}^{*}\right)^{\prime}\left[R x A s y \cdot \operatorname{Var}\left[\widehat{\beta}^{*}\right]_{x R^{\prime}}\right]^{-1}\left(R \widehat{\beta}^{*}\right)
$$

Where $\widehat{\beta}^{*}$ is gathered by stacking the individual binary logit or probit estimates of $\beta$ (Greene, 2012).

Since $j=1, \ldots, J-1$, the logits of the first $J-1$ cumulative probabilities can be given as:

$$
\log i t[P(Y \leq j)]=\log \left(\frac{P(Y \leq j)}{1-P(Y \leq j)}\right)=\log \left(\frac{\pi_{1}+\ldots+\pi_{j}}{\pi_{j+1}+\ldots+\pi_{J}}\right)
$$

which are called cumulative logits. Ordinal models allow a framework for all $J$ - 1 cumulative logits. Suppose that $X$ denotes a predictor and $j=1, \ldots, J-1$, the proportional odds model can be introduced as:

$$
\log i t[P(Y \leq j)]=\alpha_{j}+\beta_{x}
$$

where $\beta$ parameter describes the effect of $X$ on the log odds of response in category $j$ or below. For the collapsed response scale, the model can be interpreted using odds ratios. The log of odds ratios are the differences between the cumulative logits at various values of $x$. Due to the proportional property, the model in Equation (4) refers to a proportional odds model. Particularly, for $x_{2}-x_{1}=1$, the odds of response below any given category multiply by $e^{\beta}$ for each unit increase in $X$ and since the model holds with $\beta=0$, then $X$ and $Y$ are statistically independent (Agresti, 1996).

The objective of the maximum likelihood estimation of parameters for the ordered probability models is to examine the estimates of $\alpha_{j}$ 's and $\beta$ 's that maximize the joint probability of obtaining the observed values. For each of the $J$ values of the ordered response, the likelihood can be written as:

$$
L=\prod_{i=1}^{n} \prod_{j=1}^{J} \operatorname{Pr}\left(y_{i}=j / x_{i}\right)^{d_{i j}}
$$

where $d_{i j}=1$ if $y_{i}=j$, and 0 otherwise. Hence, for any observation, the $d_{i j}$ refer to a set of $J$ dummy variables, only one of which equals to 1 . The log-likelihood with respect to model quantities for the cumulative logit and probit models is given by as follows (Powers \& Xie, 2000):

$$
\log L=\sum_{i=1}^{n} \sum_{j=1}^{J} d_{i j} \log \left[F\left(\alpha_{j}+x_{j}^{\prime} \beta\right)-F\left(\alpha_{j-1}+x_{i}^{\prime} \beta\right)\right]
$$

\subsection{Study Design, Sample and Data Collection}

The study was conducted during the late of 2013 in three public hospitals of Erzurum, northeastern Turkey which provides a variety of health care services especially both for the city and the East Anatolian region. According to 2013 Health Statistics Yearbook Newsletter, the northeastern Turkey provides health care services with 62 hospitals. The total number of beds was 6,519 and the total number of physicians per 100,000 patients were 148 (Turkish Ministry of Health, 2014a). In particular, Erzurum city hosts 23 hospitals (20 public, 2 private hospitals and a university hospital) with a total of 3,286 beds (Turkish Ministry of Health, 2014b). The study utilized the data from a self-administered and written-questionnaire which was distributed to 601 patients who had received outpatient care at various units of Palandöken Public Hospital, Atatürk University Research Hospital, and Regional Training and Research Hospital. The corresponding survey performs a stratified sampling 
method to keep the level of representation both proportional and as high as possible. The Cronbach alpha value was found as 0.943 satisfying the minimum 0.70 recommended by Nunnally (1978) for relatively high internal consistency. The questionnaire involved detailed questions about both respondents' campus recreational sports and cultural facilities participation and their demographic background. Following the data collected from the hospital information system of each hospitals, the number of outpatients during the sample period was 769,060 for Atatürk University Research Hospital. Total outpatients were 405,509 for Regional Training and Research Hospital and 664.600 for Palandöken Public Hospital. Thus, the total number of outpatients during the sample period was $1,839,169$. The minimum sample size of the questionnaire was calculated with respect to the following formula:

$$
n=\frac{N P Q Z^{2}}{(N-1) d^{2}+P Q Z^{2}}
$$

where $n$ denotes the sample size; $N$ denotes the population size; $P=$ the probability of the occurrence for a given event; $Q=1-P ; Z$ denotes the test statistic under the $(1-\alpha) \%$ significance level; and finally $d$ denotes the tolerance. In this respect, the minimum representative sample size of the survey can be calculated as follows (Özer, 2004):

$$
n=\frac{(1,839,169)(0.5)(0.5)(1.96)^{2}}{(1,839,169-1)(0.05)^{2}+(0.5)(0.5)(1.96)^{2}} \cong 384
$$

As shown in Equation (8), 601 respondents exceed the number of minimum sample size.

\section{Results}

\subsection{Descriptive Statistics}

Table 1 indicates descriptive statistics of independent variables used in the model. As presented in Table 1, more than half of the respondents (55.2\%) were men and 54\% of them were aged between less than 25 and 34 . The percentage of outpatients who had received care at Palandöken Public Hospital was 35.9, where outpatients of Atatürk University Research Hospital and Regional Training and Research Hospital were second and third with 32.3 and 31.8 percentages, respectively. About $63 \%$ of the respondents $(62.3 \%)$ were married and more than half of them (50.9\%) had monthly income ranged between 1,001 Turkish liras (TL) and 2,000 TL. About $60 \%$ of the respondents $(60.5 \%)$ were secondary or higher educated, while more than half of them $(56.9 \%)$ were unemployed (including students, housewives) or self-employed (including farmers). Most of the respondents $(63.7 \%)$ were living in city center as a resindential place and again most of them (62.2\%) were settled in inner city. For more than half of the respondents $(50.9 \%)$, the household size was between five and eight individuals, whereas almost $58 \%$ of them (58.2\%) had Bag-Kur, pension fund or SSK as a health insurance. Results revealed that very most of the respondents $(74.4 \%)$ directly contacted with the corresponding public hospital and more than half of them (57.2\%) had a sufficient information about the availability of private hospitals in the city.

Table 1. Descriptive statistics of variables

\begin{tabular}{llllll}
\hline Variable & Frequency & Percent & Variable & Frequency & Percent \\
\hline Gender & & & Occupation & & \\
Male & 332 & 55.20 & Officer & 73 & 14.10 \\
Female & 269 & 44.80 & Worker & 108 & 18.00 \\
Age group & & & Craftsman/retired & 78 & 13.00 \\
$<25$ & 127 & 21.10 & Unemployed/self-employed & 342 & 56.90 \\
$25 \sim 34$ & 198 & 32.90 & Residential place & & \\
$34 \sim 44$ & 122 & 20.30 & Village/town & 155 & 25.80 \\
$44 \sim 54$ & 94 & 15.60 & County center & 63 & 10.50 \\
$>54$ & 60 & 10.10 & City center & 383 & 63.70 \\
Type of hospital & & & Settlement & & \\
University Hospital & 194 & 32.30 & Inner city & 374 & 62.20 \\
Palandöken Hospital & 216 & 35.90 & Rural of the city & 128 & 21.30 \\
\hline
\end{tabular}




\begin{tabular}{|c|c|c|c|c|c|}
\hline Variable & Frequency & Percent & Variable & Frequency & Percent \\
\hline Reg. Tra. Res. Hospital & 191 & 31.80 & From another city & 99 & 16.50 \\
\hline Marital status & & & Household size & & \\
\hline Married & 380 & 63.20 & $1 \sim 4$ & 267 & 44.40 \\
\hline Single & 221 & 36.80 & $5 \sim 8$ & 306 & 50.90 \\
\hline Monthly income & & & $>8$ & 28 & 4.70 \\
\hline$<1000 \mathrm{TL}$ & 246 & 40.90 & Health insurance & & \\
\hline $1000 \sim 2000 \mathrm{TL}$ & 306 & 50.90 & Bag-kur/Pension fund/ SSK & 350 & 58.20 \\
\hline$>2000 \mathrm{TL}$ & 49 & 18.20 & Green card & 106 & 17.60 \\
\hline Education level & & & Other insurance & 116 & 19.30 \\
\hline Illiterate & 48 & 8.00 & No insurance & 29 & 4.90 \\
\hline Literate & 58 & 9.70 & Type of contact & & \\
\hline Primary education & 142 & 23.60 & Appointment & 91 & 15.10 \\
\hline Secondary education & 222 & 36.90 & Direct & 447 & 74.40 \\
\hline Higher education & 131 & 21.80 & Transfer from another hospital & 63 & 10.50 \\
\hline Overall satisfaction & & & Information about private hospital & & \\
\hline Very dissatisfied & 21 & 3.50 & Yes & 344 & 57.20 \\
\hline Dissatisfied & 40 & 6.70 & No & 257 & 42.80 \\
\hline Moderate & 100 & 16.60 & & & \\
\hline Satisfied & 236 & 39.30 & & & \\
\hline Very satisfied & 204 & 33.90 & & & \\
\hline
\end{tabular}

\subsection{Estimation Results}

Table 2 indicates the ordered logit model estimation results to determine the influencing factors of outpatient satisfaction with three public hospitals in Erzurum city. The dependent variable of this study was the patients' overall satisfaction with outpatient services in public hospitals, which was ordinal in nature, where 1,2,3, 4, and 5 stand for 'very dissatisfied, 'dissatisfied ', 'moderate', 'satisfied', and 'very satisfied', respectively. Therefore, an ordered logit model was used to analyze the impact of independent variables on the underlying dependent variable. For this purpose, dummy variables were used in the statistical model to illustrate the estimation results regarding five categories. The model was statistically significant at $99 \%$ level of significance (log-likelihood value $=-743,362, p<.01)$ and fits well with very small values of Akaike and Bayesian Information Criteria. The interpretation of the estimates was performed using the corresponding odds ratios (OR).

Estimation results revealed that type of hospital was a significant contributor of outpatient satisfaction in three public hospitals. Specifically, holding all other variables constant, the odds of very satisfied outpatients in Palandöken Public Hospital versus the combined satisfaction levels were almost two times $(\mathrm{OR}=1.96, p<.01$, $90 \% \mathrm{CI}=1.43-2.69$ ) higher than other types of hospitals. Likewise, the odds of the combined categories of very satisfied, satisfied, moderate, and dissatisfied versus very dissatisfied were two times higher for other types of hospitals, given the other variables were held constant in the model. Similarly, the odds of very satisfied outpatients in Regional Training and Research Hospital versus the combined satisfaction levels were almost 2.8 times $(\mathrm{OR}=2.76, p<.01,90 \% \mathrm{CI}=1.98-3.85)$ higher than other types of hospitals when all other variables were hold constant. Another statistically significant variable that might have an effect on outpatient satisfaction was patients' marital status. Accordingly, married outpatients had about 1.7 times $(\mathrm{OR}=1.72, p<.05,90 \% \mathrm{CI}=$ 1.18 - 2.52) higher odds of being very satisfied versus the other combined satisfaction levels than single counterparts. Moreover, age was another important influencer of outpatient satisfaction. Outpatients aged between twenty-five and thirty-four had about 0.6 times $(\mathrm{OR}=0.57, p<.05,90 \% \mathrm{CI}=0.37-0.88)$ lower odds of being very satisfied versus the combined satisfaction levels than other age groups. Similar interpretations can be made for the odds of very satisfied outpatients aged forty-five and fifty-four and higher than fifty-five versus the combined other satisfaction levels that were almost $0.4(\mathrm{OR}=0.41, p<.05,90 \% \mathrm{CI}=0.23-0.73)$ and 0.5 times $(\mathrm{OR}=0.46, p<.05,90 \% \mathrm{CI}=0.24-0.88)$ less than the other combined levels, respectively. Education level was another factor of indicating outpatients' dissatisfaction. Estimates suggested that secondary and higher educated outpatients had about 0.5 times $(\mathrm{OR}=0.48, p<.05,90 \% \mathrm{CI}=0.27-0.87)$ and about 0.3 times $(\mathrm{OR}=$ $0.33, p<.01,90 \% \mathrm{CI}=0.17-0.65)$ lower odds of being very satisfied than other education levels versus the combined satisfaction levels. 
Table 2. Ordered logit model estimation of the factors affecting outpatient satisfaction

\begin{tabular}{|c|c|c|c|c|c|}
\hline Independent variable & OR & Std. Err. & $\mathbf{z}$ & Sig. & {$[90 \% \mathrm{CI}]$} \\
\hline \multicolumn{6}{|l|}{ Type of hospital (base University Hosp.) } \\
\hline Palandöken Hospital & 1.96 & 0.377 & 3.49 & & \\
\hline Regional Training and Research Hospital & 2.76 & 0.560 & 5.00 & $0.000^{*}$ & $\begin{array}{l}1.43-2.69 \\
1.08-3.85\end{array}$ \\
\hline \multicolumn{6}{|l|}{ Gender } \\
\hline Male & 1.00 & 0.179 & 0.01 & 0.996 & $0.74-1.34$ \\
\hline \multicolumn{6}{|l|}{ Marital status } \\
\hline Married & 1.72 & 0.398 & 2.36 & $0018 * *$ & $118-252$ \\
\hline \multicolumn{6}{|l|}{ Age group (base aged $<25$ ) } \\
\hline $25-34$ & 0.57 & 0.151 & -2.13 & & \\
\hline $35-44$ & 0.69 & 0.219 & -1.16 & $0.034^{* *}$ & $0.37-0.88$ \\
\hline $45-54$ & 0.41 & 0.143 & -2.56 & 0.246 & $0.41-1.17$ \\
\hline$>54$ & 0.46 & 0.181 & -1.96 & $0.009^{*}$ & $0.23-0.73$ \\
\hline \multicolumn{6}{|l|}{ Education level (base literate) } \\
\hline Illiterate & 0.53 & 0.208 & -1.61 & & \\
\hline Primary education & 0.61 & 0.205 & -1.48 & 0.107 & $0.28-1.01$ \\
\hline Secondary education & 0.48 & 0.173 & -2.04 & 0.139 & $0.35-1.06$ \\
\hline Higher education & 0.33 & 0.135 & -2.71 & $0.042^{* *}$ & $0.27-0.87$ \\
\hline \multicolumn{6}{|l|}{ Occupation (base unemployed) } \\
\hline Officer & 1.25 & 0.376 & 0.75 & & \\
\hline Worker & 1.87 & 0.494 & 2.37 & 0.455 & $\begin{array}{l}0.76-2.05 \\
1.21-2.80\end{array}$ \\
\hline Craftsman/retired & 1.07 & 0.306 & 0.25 & $0.018^{* *}$ & $\begin{array}{l}1.21-2.89 \\
0.67-1.71\end{array}$ \\
\hline \multicolumn{6}{|l|}{ Settlement (base rural of the city) } \\
\hline Inner city & 1.19 & 0.360 & 0.58 & & \\
\hline From another city & 0.85 & 0.246 & -0.56 & 0.002 & $0.12-1.90$ \\
\hline \multicolumn{6}{|l|}{ Residential place (base village/town) } \\
\hline County center & 1.31 & 0.399 & 0.90 & 0.369 & $0.80-2.17$ \\
\hline City center & 1.85 & 0.546 & 2.07 & $0.038^{* *}$ & $1.13-3.00$ \\
\hline \multicolumn{6}{|l|}{ Household size (base 1 - 4) } \\
\hline 5 - 8 people & 1.00 & 0.173 & 0.01 & 0.996 & $0.75-1.33$ \\
\hline$>8$ peopşe & 1.69 & 0.713 & 1.25 & 0.211 & $0.85-3.38$ \\
\hline \multicolumn{6}{|l|}{ Monthly income (base > 2000 TL) } \\
\hline$<1000 \mathrm{TL}$ & 0.76 & 0.258 & -0.80 & 0.421 & $0.44-1.33$ \\
\hline $1000-2000 \mathrm{TL}$ & 0.58 & 0.184 & -1.72 & $0.085^{* * *}$ & $0.34-0.98$ \\
\hline \multicolumn{6}{|l|}{ Health insurance (base no insurance) } \\
\hline Bag-kur/Pension fund/SSK & 1.03 & 0.257 & 0.11 & 0.915 & $0.68-1.55$ \\
\hline Green card & 1.19 & 0.336 & 0.63 & 0.531 & $0.75-1.90$ \\
\hline Other insurance & 0.87 & 0.352 & -0.35 & 0.725 & $0.44-1.69$ \\
\hline \multicolumn{6}{|l|}{ Type of contact (base appointment) } \\
\hline Direct & 1.02 & 0.227 & 0.07 & 0.944 & $0.61-0.99$ \\
\hline Transfer from another hospital & 0.67 & 0.226 & -1.19 & 0.233 & $0.38-1.17$ \\
\hline \multicolumn{6}{|l|}{ Information about private hospital } \\
\hline Yes & 0.64 & 0.109 & -2.61 & $0.009^{*}$ & $0.49-0.85$ \\
\hline \multicolumn{6}{|l|}{ /cut1 } \\
\hline \multicolumn{6}{|l|}{ /cut2 } \\
\hline \multicolumn{6}{|l|}{ /cut3 } \\
\hline \multicolumn{6}{|l|}{ /cut4 } \\
\hline Number of observations: 601 & $\begin{aligned}-5.05 \\
-265\end{aligned}$ & $\begin{array}{l}0.050 \\
0.605\end{array}$ & & & \\
\hline Log-likelihood full model: -743.362 & $\begin{array}{r}-2.65 \\
1.27\end{array}$ & 0.605 & & & \\
\hline Log-likelihood intercept only: -799.188 & -1.37 & 0.594 & & & \\
\hline LR chi-square(17): 103.651 & 0.54 & 0.591 & & & \\
\hline \multicolumn{6}{|l|}{$\rho^{2}: 0.065$} \\
\hline \multicolumn{6}{|l|}{ Akaike Information Criterion: 2.597} \\
\hline Bayesian Information Criterion: -2139.678 & & & & & \\
\hline
\end{tabular}

*significant at $99 \%$; ** significant at $95 \%$; *** significant at $90 \%$ 
According to estimation results it was found that outpatient occupation had a significant effect on patient satisfaction. For occupation group, worker was the significant category, where the odds of very satisfied workers versus the combined satisfaction levels were almost 1.90 times $(\mathrm{OR}=1.87, p<.05,90 \% \mathrm{CI}=1.21-2.89)$ higher than other occupation groups. It was also found that outpatient's residential place might have been effective on his/her satisfaction. The odds of very satisfied outpatients who live in city center versus the combined satisfaction levels were about 1.9 times $(\mathrm{OR}=1.85, p<.05,90 \% \mathrm{CI}=1.13-3.00)$ higher than the other residence place categories holding the other variables constant. Monthly income was the only significant factor which was found significant at $90 \%$ level of significance, while the odds of very satisfied outpatients who had monthly income between 1001 and $2000 \mathrm{TL}$ versus the combined satisfaction levels were 0.58 times $(\mathrm{OR}=0.58$, $p<.10,90 \% \mathrm{CI}=0.34-0.98$ ) lower than the other income levels holding the other variables constant. Finally, information about private hospital was the last significant factor that may influence outpatient satisfaction. Specifically, the odds of very satisfied outpatients who had information about private hospitals in the city versus the combined other satisfaction levels were 0.64 times $(\mathrm{OR}=0.64, p<.05,90 \% \mathrm{CI}=0.49-0.85)$ lower than outpatients who had not such information.

The marginal effects of the independent variables on satisfaction levels showed the percentage increase or decrease of the relevant factor on the dependent variable. As shown in Table 3, patients who had outpatient care at Palandöken Hospital were $15 \%(\mathrm{dy} / \mathrm{dx}=0.150)$ more very satisfied versus the combined other satisfaction levels than other hospitals. Similarly, outpatients at Regional Training and Research Hospital versus the combined other satisfaction levels were $23 \%(\mathrm{dy} / \mathrm{dx}=0.230)$ more likely to be very satisfied than other type of hospitals. Married outpatients were $11.5 \%(\mathrm{dy} / \mathrm{dx}=0.115)$ more likely to very satisfied than single counterparts. Estimation results exhibited that outpatients aged between twenty-five and thirty-four, between forty-five and fifty-four and aged more than fifty-five were $11.8 \%(\mathrm{dy} / \mathrm{dx}=-0.118), 17 \%(\mathrm{dy} / \mathrm{dx}=-0.170)$, and $14.6 \%(\mathrm{dy} / \mathrm{dx}=$ -0.146) less likely to be very satisfied with hospital services than other combined age groups, respectively. Secondary and higher educated outpatients were also $15.3 \%(\mathrm{dy} / \mathrm{dx}=-0.153)$ and $21 \%(\mathrm{dy} / \mathrm{dx}=-0.210)$ less likely to be very satisfied than other combined education levels, respectively. Results revealed that workers were $14.4 \%(\mathrm{dy} / \mathrm{dx}=0.144)$ more likely to be very satisfied than the combined other occupation groups. Outpatients living in the city center were $12.9 \%$ more likely to be very satisfied than the other combined residential place categories. Outpatients who had monthly income between 1001 and 2000 TL were $11.8 \%$ less likely to be very satisfied than the combined other income levels. Finally, outpatients who were aware of the private hospitals in the city were $9.7 \%$ less likely to be very satisfied than outpatients who did not have information about private hospitals.

Table 3. Marginal effects

\begin{tabular}{lc}
\hline Independent variable & $\mathbf{d y} / \mathbf{d x}$ \\
\hline Type of hospital & \\
Palandöken Hospital & 0.150 \\
Regional Training and Research Hospital & 0.230 \\
Marital status & \\
Married & 0.115 \\
Age group & \\
$25-34$ & -0.118 \\
$45-54$ & -0.170 \\
$>55$ & -0.146 \\
Education level & \\
Secondary education & -0.153 \\
Higher education & -0.210 \\
Occupation & \\
Worker & 0.144 \\
Residential place & \\
City center & 0.129 \\
Monthly income & \\
1000 - 2000 & -0.118 \\
Information about private hospital & -0.097 \\
\hline
\end{tabular}




\subsection{Model Specification}

Table 4. Multicollinearity test

\begin{tabular}{|c|c|c|}
\hline Independent variable & VIF & 1/VIF \\
\hline \multicolumn{3}{|l|}{ Type of hospital } \\
\hline Palandöken Hospital & 1.45 & \\
\hline Regional Training and Research Hospital & 1.43 & 0.690 \\
\hline \multicolumn{3}{|l|}{ Gender } \\
\hline Male & 1.37 & \\
\hline \multicolumn{3}{|l|}{ Marital status } \\
\hline Married & 2.06 & \\
\hline \multicolumn{3}{|l|}{ Age group (base aged $<25$ ) } \\
\hline $25-34$ & 2.62 & \\
\hline $35-44$ & 2.71 & $\begin{array}{l}0.381 \\
0.369\end{array}$ \\
\hline $45-54$ & 2.74 & $\begin{array}{l}0.369 \\
0.365\end{array}$ \\
\hline$>55$ & 2.27 & 0.365 \\
\hline \multicolumn{3}{|l|}{ Education level (base literate) } \\
\hline Illiterate & 2.18 & \\
\hline Primary education & 3.48 & 0.459 \\
\hline Secondary education & 5.07 & 0.287 \\
\hline Higher education & 4.69 & 0.197 \\
\hline \multicolumn{3}{|l|}{ Occupation (base unemployed) } \\
\hline Officer & 1.64 & \\
\hline Worker & 1.67 & 0.611 \\
\hline Craftsman/retired & 1.55 & 0.599 \\
\hline \multicolumn{3}{|l|}{ Settlement (base rural of the city) } \\
\hline Inner city & 3.55 & \\
\hline From another city & 2.05 & 0.281 \\
\hline \multicolumn{3}{|l|}{ Residential place (base village/town) } \\
\hline County center & 1.50 & 0.668 \\
\hline City center & 3.31 & 0.302 \\
\hline \multicolumn{3}{|l|}{ Household size (base 1 - 4) } \\
\hline 5 - 8 people & 1.27 & 0.785 \\
\hline$\geq 9$ people & 1.21 & 0.823 \\
\hline \multicolumn{3}{|l|}{ Monthly income (base $\geq 2001$ TL) } \\
\hline$<1000 \mathrm{TL}$ & 4.31 & 0.232 \\
\hline $1001-2000 \mathrm{TL}$ & 3.92 & 0.255 \\
\hline \multicolumn{3}{|l|}{ Health insurance (base no insurance) } \\
\hline Bag-kur/Pension fund/SSK & 2.53 & 0.394 \\
\hline Green card & 1.98 & 0.504 \\
\hline Other insurance & 1.36 & 0.736 \\
\hline \multicolumn{3}{|l|}{ Type of contact (base appointment) } \\
\hline Direct & 1.69 & 0.592 \\
\hline Transfer from another hospital & 1.91 & 0.522 \\
\hline \multicolumn{3}{|l|}{ Information about private hospital } \\
\hline Yes & 1.17 & 0.854 \\
\hline Mean VIF & 2.37 & \\
\hline
\end{tabular}

The Wald statistic of parallel regression assumption proposed by Brant (1990) suggests that the null hypothesis implies there is no difference in the coefficients between models, a non-significant result ensures that the parallel regression assumption is not violated. Since the overall significance $\left(x^{2}=61.81, p>.05, \mathrm{df}=87\right)$ was higher than $95 \%$ level of significance, the estimation results of the fitted model was statistically sound and the parallel regression assumption was not violated. On the other hand, Table 3 exhibits the variance inflation factor (VIF) 
values of the relevant independent variables included in the fitted ordered logit model. Practically, variables which have VIF values more than 10 are considered as they lead to multicollinearity problem and biased results. As shown in Table 4, none of the independent variables had VIF values more than 10 confirming the absence of multicollinearity in the data.

\section{Discussion}

This paper aims to examine potential influencers of outpatient satisfaction in three public hospitals in Erzurum, northeastern Turkey. The dependent variable of the current study was the patient satisfaction which was a discrete variable and had a natural ordering. Herein, the obtained data were estimated using an ordered logit model approach. Early descriptive results indicated that most of the patients were generally satisfied with health care services in the corresponding hospitals. This result is consistent with a very recently reported survey conducted by the Ministry of Health (Turkish Ministry of Health, 2014c). Estimation results revealed that type of hospital was a significant determinant of patient satisfaction. Specifically, Regional Training and Research Hospital had more satisfied patients than Palandöken Public Hospital. When compared, Regional Training and Research Hospital is a larger hospital than Atatürk University Research Hospital. At this point, this result is consistent with earlier studies (Kim et al., 2008; Gok \& Sezen, 2013) where patients of larger hospitals are more satisfied. Additionally, as recommended by Gok and Sezen (2013), small and medium sized hospitals may consider larger hospitals as a role model in terms of quality of health care. Similarly, in accordance with earlier findings (Demir \& Celik, 2002; Thi, 2002; Laal, 2013), the results of this study found that married patients were more likely to be very satisfied.

One noteworthy estimation result was the association between age groups and patient satisfaction. Although a negative relationship was observed, the significance of age is consistent with many earlier studies (Cohen, 1996; Sun et al., 2000, 2001; Jackson et al., 2001; Johansson et al., 2002; Rahmqvist, 2001; Demir \& Celik, 2002; Thi et al., 2002; Cheng et al., 2003; Scotti \& Stinerock, 2002; Bikker \& Thompson, 2006; Hekkert et al., 2009; Laal, 2013; Farley et al., 2014; Mercer et al., 2014). Particularly, results of marginal effects indicated that middle-aged and elderly were less satisfied than other age groups. Health care managers and policy makers may pay attention on the corresponding age groups to keep them more satisfied. Many older patients in Turkey have the right to take their health care at home. Policy makers of the corresponding hospitals should encourage older patients to frequently use this facility that may have an effect on decreasing dissatisfaction. This encouragement may also improve the communication between the physician and the patient. Consequently, increasing patient loyalty may be achieved.

Education level of the patients was determined as another significant factor. This result shows consistency with earlier work (Demir \& Celik, 2002; Johansson et al., 2002; Cheng et al., 2003; Bikker \& Thompson, 2006; Hekkert et al., 2009; Al-Borie \& Damanhouri, 2013; Laal, 2013; Çelik et al., 2014; Farley et al., 2014). Marginal effects values suggested that higher-educated patients were less satisfied than their counterparts. Health care managers may seek the reasons of this dissatisfaction and re-arrange their policies for higher-educated patients. Estimation results revealed that patients' occupation was a significant factor of patient satisfaction which was consistent with earlier research (Al-Borie \& Damanhouri, 2011; Laal, 2013; Mohd \& Chakravarty, 2014). Workers were more likely to be very satisfied than their counterparts confirming the success of health care policy on this group despite none of health insurance category was found as statistically significant. Moreover, residential place was a significant factor which was consistent with a most recent study (Laal, 2013). It was found that patients who live in city center were more likely to be satisfied. However, health care providers may particularly question why patients coming from other neighbor cities were not significantly satisfied, despite Erzurum is adopted as one of the regional centers of the health care services. Because, satisfying the corresponding patient groups are crucial for improved patient loyalty and city image, health care managers should intensively consider improving their satisfaction as a further health care policy.

Estimation results revealed that middle income patients were less satisfied than their counterparts. This result is consistent with some past research (Cohen, 1996; Frank et al., 2009; Al-Borie \& Damanhouri, 2013) where income level of patients was statistically significant. Health care managers of public hospitals should pay attention to improve their quality of health services, otherwise middle and high income patients may prefer private hospitals than public hospitals unless a strong patient loyalty was not guaranteed. In that sense, another important result of this study was private hospital information. So that, patients who were aware of private hospitals in the city were less satisfied who may consider them as a better alternative. This result shows consistency with earlier studies (Taner \& Antony, 2006; Tateke et al., 2012), when patients of private hospitals were more satisfied. Dağdeviren and Akturk (2004) suggest that lack of a competitive environment is one of the major issues of Turkish health sector. Following this suggestion, the competitiveness of both public and private 
hospitals may improve quality of health. There are two private hospitals in Erzurum city as alternative health care providers. Policy makers of public hospitals may benchmark the quality of health care with private hospitals to seek their strengths and weaknesses.

This study is limited to outpatient satisfaction with only three public hospitals in Erzurum city and for simplicity, demographic and socio-economic factors are mainly considered. However, Miranda et al. (2010) suggest that most health care managers tend to concentrate on healthcare infrastructure although it has relatively minimum effect on quality of health care against health care staff and patient factors. Further studies are needed which may enable benchmarks among other regional cities and including other patient groups, background factors, and private hospitals. Naidu (2009) proposes a multi-disciplinary approach for the operationalization of patient satisfaction and health care quality combining patient inputs as well as evaluation of health care providers. As suggested by a comprehensive earlier review study (Taylor \& Benger, 2004), future research of patient satisfaction should be based on an approach involving both qualitative and quantitative methods.

\section{References}

Abreu, M. N. S., Siqueira, A. L., Cardoso, C. S., \& Caiaffa, W. T. (2008). Ordinal logistic regression models: Application in quality of science studies. Cad Saude Publica, 24(4), 581-591.

Agresti, A. (1996). An Introduction to Categorical Data Analysis. New York: John Wiley \& Sons, Inc.

Al-Borie, H. M., \& Damanhouri, A. M. (2013). Patients' satisfaction of service quality in Saudi hospitals: A SERVQUAL analysis. International Journal of Health Care Quality Assurance, 26(1), 20-30. http://dx.doi. org/10.1108/09526861311288613

Amemiya, T. (1985). Advanced Econometrics. Cambridge, Massachusetts: Harvard University Press.

Amemiya, T. (1994). Introduction to Statistics and Econometrics. Cambridge, Massachusetts: Harvard University Press.

Andaleeb, S. S., Siddiqui, N., \& Khandakar, S. (2007). Patient satisfaction with health services in Bangladesh. Health Policy and Planning, 22(4), 263-273. http://dx.doi.org/10.1093/heapol/czm017

Avis, M., Bond, M., \& Arthur, A. (1997). Questioning patient satisfaction: An empirical investigation in two outpatient clinics. Social Science \& Medicine, 44(1), 85-92. http://dx.doi.org/10.1016/S0277-9536(96) 00140-2

Baalbaki, I., Ahmed, Z. A., Pashtenko, V. H., \& Makarem, S. (2008). Patient satisfaction with healthcare delivery systems. International Journal of Pharmaceutical and Healthcare Marketing, 2(1), 47-62. http://dx.doi.org/ 10.1108/17506120810865424

Bikker, A. P., \& Thompson, A. G. H. (2006). Predicting and comparing patient satisfaction in four different modes of health care across a nation. Social Science \& Medicine, 63(6), 1671-1683. http://dx.doi.org/10. 1016/j.socscimed.2006.03.022

Borooah, V. K. (2002). Logit and Probit: Ordered and Multinomial Models. Thousand Oaks, California: SAGE Publications.

Çelik, A. K., Oktay, E., \& Akbaba, A. İ. (2014). An ordered logit analysis of inpatient and outpatient satisfaction in a Turkish state hospital. İstanbul Üniversitesi Isşletme Fakültesi Dergisi, 43(2), 237-250. Retrieved from http://www.ifdergisi.org/index.php/ifdergi/article/view/391

Chahal, H., \& Mehta, S. (2013). Modeling patient satisfaction construct in the Indian health care context. International Journal of Pharmaceutical and Healthcare Marketing, 7(1), 75-92. http://dx.doi.org/10.1108/ 17506121311315445

Chang, W. J., \& Chang, Y. H. (2013). Patient satisfaction analysis: Identifying key drivers and enhancing service quality of dental care. Journal of Dental Sciences, 8(3), 239-247. http://dx.doi.org/10.1016/j.jds.2012. 10.006

Cheng, S. H., Yang, M. C., \& Chiang, T. L. (2003). Patient satisfaction with and recommendation of a hospital: Effects of interpersonal and technical aspects of hospital care. International Journal for Quality in Health Care, 15(4), 345-355. http://dx.doi.org/10.1093/intqhe/mzg045

Cohen, G. (1996). Age and health status in a patient satisfaction survey. Social Science \& Medicine, 42(7), 1085-1093. http://dx.doi.org/10.1016/0277-9536(95)00315-0

Dağdeviren, N., \& Akturk, Z. (2004). An evaluation of patient satisfaction in Turkey with the EUROPEP 
instrument. Yonsei Medical Journal, 45(1), 23-28. http://dx.doi.org/10.3349/ymj.2004.45.1.23

Demir, C., \& Celik, Y. (2002). Determinants of patient satisfaction in a military teaching hospital. Journal for Healthcare Quality, 24(2), 30-34. http://dx.doi.org/10.1111/j.1945-1474.2002.tb00416.x

Dufrene, R. L. (2000). An evaluation of a patient satisfaction survey: Validity and reliability. Evaluation and Program Planning, 23(3), 293-300. http://dx.doi.org/10.1016/S0149-7189(00)00015-X

Farley, H., Enquidanos, E. R., Coletti, C. M., Honigman, L., Mazzeo, A., Pinson, T. B., ..., Wiler, J. L. (2014). Patient satisfaction surveys and quality of care: An information paper. Annals of Emergency Medicine, 64(4), 351-357. http://dx.doi.org/10.1016/j.annemergmed.2014.02.021

Fitzpatric, R. (1991). Surveys of patient satisfaction: I--Important general considerations. British Medical Journal, 302(6781), 887-889. http://dx.doi.org/10.1136/bmj.302.6781.887

Frank, B., Sudo, S., \& Enkawa, T. (2009). Interpreting time series of patient satisfaction: Macro vs. micro components. Journal of Hospital Marketing \& Public Relations, 19(1), 15-39. http://dx.doi.org/10.1080/ 15390940802581572

French, S., Lindo, J. L., Williams, J. E. W., \& Williams-Johnson, J. (2014). Doctor at triage - effect on waiting time and patient satisfaction in a Jamaican hospital. International Emergency Nursing, 22(3), 123-126. http://dx.doi.org/10.1016/j.ienj.2013.06.001

Gill, L., \& White, L. (2009). A critical review of patient satisfaction. Leadership in Health Services, 22(1), 8-19. http://dx.doi.org/10.1108/17511870910927994

Gok, M. S., \& Sezen, B. (2013). Analyzing the ambiguous relationship between efficiency, quality and patient satisfaction in healthcare services: The case of public hospitals in Turkey. Health Policy, 111(3), 290-300. http://dx.doi.org/10.1016/j.healthpol.2013.05.010

Greene, W. H. (2012). Econometric Analysis. New Jersey: Prentice Hall.

Grogan, S., Conner, M., Norman, P., Willits, D., \& Porter, I. (2000). Validation of a questionnaire measuring patient satisfaction with general practitioner services. Quality in Health Care, 9(4), 210-215. http://dx.doi. org/10.1136/qhc.9.4.210

Hekkert, K. D., Cihangir, S., Kleefstra, S. M., van den Berg, B., \& Kool, R. B. (2009). Patient satisfaction revisited: A multilevel approach. Social Science \& Medicine, 69(1), 68-75. http://dx.doi.org/10.1016/j.socscimed. 2009.04.016

Hsieh, M. O., \& Kagle, J. D. (1991). Understanding patient satisfaction and dissatisfaction with health care. Health \& Social Work, 16(4), 281-290.

Jackson, J. L., Chamberlin, J., \& Kroenke, K. (2001). Predictors of patient satisfaction. Social Science \& Medicine, 52(4), 609-620. http://dx.doi.org/10.1016/S0277-9536(00)00164-7

Johannessen, G., Eikeland, A., Stubberud, D. G., \& Fagerstöm, L. (2011). A descriptive study of patient satisfaction and the structural factors of Norwegian intensive care nursing. Intensive and Critical Care Nursing, 27(5), 281-289. http://dx.doi.org/10.1016/j.iccn.2011.07.004

Johansson, P., Oléni, M., \& Fridlund, B. (2002). Patient satisfaction with nursing care in the context of health care: A literature study. Scandinavian Journal of Caring Sciences, 16(4), 337-344. http://dx.doi.org/10.1046/j. 1471-6712.2002.00094.x

Kaldenberg, D. O. (2001). Patient satisfaction and health status. Health Marketing Quarterly, 18(3-4), 81-101. http://dx.doi.org/10.1300/J026v18n03_07

Kim, Y. K., Cho, C. H., Ahn, S. K., Goh, I. H., \& Kim, H. J. (2008). A study on medical services quality and its influence upon value of care and patient satisfaction - Focusing upon outpatients in a large-sized hospital. Total Quality Management \& Business Excellence, 19(11), 1155-1171. http://dx.doi.org/10.1080/147833 60802323594

Laal, M. (2013). Inpatient's perspective on nursing care; affecting factors. Procedia - Social and Behavioral Sciences, 84, 243-247. http://dx.doi.org/10.1016/j.sbspro.2013.06.543

Levin, R. (2005). Measuring patient satisfaction. Journal of the American Dental Association, 136(3), 362-363. http://dx.doi.org/10.14219/jada.archive.2005.0178

McKinley, R. K., Manku-Scott, T., Hastings, A. M., French, D. P., \& Baker, R. (1997). Reliability and validity of a new measure of patient satisfaction with out of hours primary medical care in the United Kingdom: 
Development of a patient questionnaire. British Medical Journal, 314(7075), 193-198. http://dx.doi.org/10. 1136/bmj.314.7075.193

Mercer, M. P., Hernandez-Boussard, T., Mahadevan, S. V., \& Strehlow, M. C. (2014). Physician identification and patient satisfaction in the emergency department: Are they related? The Journal of Emergency Medicine, 46(5), 711-718. http://dx.doi.org/10.1016/j.jemermed.2013.08.036

Merkouris, A., Papathanassoglou, E. D. E., \& Lemonidou, C. (2004). Evaluation of patient satisfaction with nursing care: Quantitative or qualitative approach? International Journal of Nursing Studies, 41(4), 355-367. http://dx.doi.org/10.1016/j.ijnurstu.2003.10.006

Miranda, F. J., Chamorro, A., Murillo, L. R., \& Vega, J. (2010). Assessing primary healthcare services quality in Spain: Managers vs. patients perceptions. The Service Industries Journal, 30(13), 2137-2149. http://dx.doi. org/10.1080/02642060903215055

Mohd, A., \& Chakravarty, A. (2014). Patient satisfaction with services of the outpatient department. Medical Journal Armed Forces India, 70(3), 237-242. http://dx.doi.org/10.1016/j.mjafi.2013.06.010

Mpinga, E. K., \& Chastonay, P. (2011). Satisfaction of patients: A right to health indicator? Health Policy, Vol. 100(2-3), 144-150. http://dx.doi.org/10.1016/j.healthpol.2010.11.001

Naidu, A. (2009). Factors affecting patient satisfaction and healthcare quality. International Journal of Health Care Quality Assurance, 22(4), 366-381. http://dx.doi.org/10.1108/09526860910964834

Nguyen Thi, P. L., Briançon, S., Empereur, F., \& Guillemin, F. (2002). Factors determining inpatient satisfaction with care. Social Science \& Medicine, 54(4), 493-504. http://dx.doi.org/10.1016/S0277-9536(01)00045-4

Nunnally, J. C. (1978). Psychometric Theory. New York: Mc-Graw-Hill.

Oluwadiya, K., Olatoke, S. A., Ariba, A. J., Omotosho, O. A., \& Olakulehin, O. A. (2010). Patients' satisfaction with emergency care and priorities for change in a university teaching hospital in Nigeria. International Emergency Nursing, 18(4), 203-209. http://dx.doi.org/10.1016/j.ienj.2009.12.003

Otani, K., Kim, B. J., Waterman, B., Boslaugh, S., Klinkenberg, W. D., \& Dunagan, W. C. (2012). Patient satisfaction and organizational impact: A hierarchical linear modeling approach. Health Marketing Quarterly, 29(3), 256-269. http://dx.doi.org/10.1080/07359683.2012.705724

Özer, H. (2004). Nitel Değişkenli Ekonometrik Modeller: Teori ve Bir Uygulama (in Turkish). Ankara: Nobel Yayın Dağıtım.

Powers, D. A., \& Xie, Y. (2000). Statistical Methods for Categorical Data Analysis. San Diego, California: Academic Press.

Rahmqvist, M. (2001). Patient satisfaction in relation to age, health status and other background factors: A model for comparisons of care units. International Journal for Quality in Health Care, 13(5), 385-390. http://dx.doi.org/10.1093/intqhe/13.5.385

Scott, A., \& Smith, R. D. (1994). Keeping the customer satisfied: Issues in the interpretation and use of patient satisfaction surveys. International Journal for Quality in Health Care, 6(4), 353-359. http://dx.doi.org/ 10.1093/intqhe/6.4.353

Scotti, D. J., \& Stinerock, R. N. (2002). Cognitive predictors of satisfaction with hospital inpatient service encounters among the elderly: A matter of trust. Journal of Hospital Marketing \& Public Relations, 14(2), 3-22. http://dx.doi.org/10.1300/J375v14n02_02

Sitzia, J. (1999). How valid and reliable are patient satisfaction data? An analysis of 195 studies. International Journal for Quality in Health Care, 11(4), 319-328. http://dx.doi.org/10.1093/intqhe/11.4.319

Staniszewska, S., \& Ahmad, L. (1999). The concepts of expectation and satisfaction: Do they capture the way patients evaluate their care? Journal of Advanced Nursing, 29(2), 364-372. http://dx.doi.org/10.1046/j.1365 $-2648.1999 .00897 . x$

Sun, B. C., Adams, J. G., \& Burstin, H. R. (2001). Validating a model of patient satisfaction with emergency care. Annals of Emergency Medicine, 38(5), 527-532. http://dx.doi.org/10.1067/mem.2001.119250

Sun, B. C., Adams, J., Orav, E. J., Rucker, D. W., Brennan, T. A., \& Burstin, H. R. (2000). Determinants of patient satisfaction and willingness to return with emergency care. Annals of Emergency Medicine, 35(5), 426-434. http://dx.doi.org/10.1016/S0196-0644(00)70003-5

Taner, T., \& Antony, J. (2006). Comparing public and private hospital care service quality in Turkey. Leadership 
in Health Services, 19(2-3), 1-10. http://dx.doi.org/10.1108/13660750610664991

Tateke, T., Woldie, M., \& Ololo, S. (2012). Determinants of patient satisfaction with outpatient health services at public and private hospitals in Addis Ababa, Ethiopia. African Journal of Primary Health Care \& Family Medicine, 4(1), 1-11. http://dx.doi.org/10.4102/phcfm.v4i1.384

Taylor, C., \& Benger, J. R. (2004). Patient satisfaction in emergency medicine. Emergency Medicine Journal, 21(5), 528-532. http://dx.doi.org/10.1136/emj.2002.003723

Tehrani, A. B., Feldman, S. R., Camacho, F. T., \& Balkrishnan, R. (2011). Patient satisfaction with outpatient medical care in the United States. Health Outcomes Research in Medicine, 2(4), e197-e202. http://dx.doi. org/10.1016/j.ehrm.2011.09.001

Turkish Ministry of Health. (2009). Health Transformation Program in Turkey Progress Report. Ankara: Ministry of Health Publications.

Turkish Ministry of Health. (2014a). 2013 Health Statistics Yearbook Newsletter. Retrieved October 13, 2014, from http://www.saglik.gov.tr/TR/dosya/1-93205/h/siy2013haberbulteni.pdf

Turkish Ministry of Health. (2014b). Public Hospital Unions-2014. Retrieved October 13, 2014, from http://www.tkhk.gov.tr/Dosyalar/35af57490d2b49bca6503ac61c8fe7d1.pdf

Turkish Ministry of Health. (2014c). Patient Satisfaction with Primary Health Care Services-2012. Ankara: Ministry of Health Publications.

Williams, B. (1994). Patient satisfaction: A valid concept? Social Science \& Medicine, 38(4), 509-516. http://dx. doi.org/10.1016/0277-9536(94)90247-X

\section{Copyrights}

Copyright for this article is retained by the author(s), with first publication rights granted to the journal.

This is an open-access article distributed under the terms and conditions of the Creative Commons Attribution license (http://creativecommons.org/licenses/by/3.0/). 